\title{
O SISTEMA PRECEDENTALISTA BRASILEIRO À LUZ DO DIREITO COMO INTEGRIDADE DE RONALD DWORKIN
}

\author{
Loiane Prado Verbicaro ${ }^{1}$ \\ Arthur Laércio Homci ${ }^{2}$
}

\begin{abstract}
RESUMO
O trabalho tem como escopo desenvolver uma fundamentação, à luz da teoria do direito, para a construção de um sistema de vinculação de precedentes no ordenamento jurídico brasileiro. A pesquisa se justifica uma vez que não basta a simples previsão legal de obrigatoriedade dos precedentes para a manutenção de um sistema precedentalista. É imprescindível a articulação a uma teoria do direito que auxilie os juízes na construção de um sistema estável, íntegro e coerente. Para tanto, a pesquisa, por intermédio de estudo teórico e bibliográfico, lastreou-se, notadamente, no pensamento de Ronald Dworkin, referente à sua teoria do direito como integridade, baseada em uma perspectiva coerentista da decisão judicial.
\end{abstract}

PALAVRA-CHAVE: Precedente. Coerência. Direito como Integridade. Ronald Dworkin. Common Law.

\section{THE BRAZILIAN PRECEDENTALIST SYSTEM UNDER ANALYSIS OF THE LAW AS INTEGRITY OF RONALD DWORKIN}

\begin{abstract}
The purpose of this paper is to develop a rationale, under analysis of the legal theory, to construct a system of binding precedents in the Brazilian legal system. The research is justified because it is not enough the simple legal prediction of obligatoriness of precedents for a maintenance of a precedental system. It is essential to articulate a legal theory that assists judges in the construction of a stable, whole and coherent system. For this, the research, by means of theoretical and bibliographical study, was based on the thought of Ronald Dworkin, referring to his theory of law as integrity, based on a coherent perspective of the judicial decision.
\end{abstract}

KEY-WORDS: Precedent. Coherence. Right as Integrity. Ronald Dworkin. Common Law.

\section{INTRODUÇÃO}

\footnotetext{
1 Doutora em Filosofia do Direito pela Universidade de Salamanca, Mestra em Direitos Fundamentais e Relações Sociais pela Universidade Federal do Pará, com período de estudo na Universidade de São Paulo (USP), Mestra em Ciência Política pela Universidade Federal do Pará, Graduada em Direito pela Universidade Federal do Pará, Coordenadora do Curso de Graduação em Direito, Vice-Coordenadora do Programa de PósGraduação Stricto Sensu do Centro Universitário do Pará; Professora da Graduação e do Programa de PósGraduação Stricto Sensu e Lato Sensu em Direito do Centro Universitário do Pará, Professora convidada da Escola Superior da Magistratura. Atualmente cursa Graduação em Filosofia na Universidade Federal do Pará. É líder do grupo de pesquisa (CNPQ): Democracia, Poder Judiciário e Direitos Humanos.

2 Doutorando em Direito pela Universidade Federal do Pará - UFPA. Mestre em Direito pela UFPA. Coordenador Adjunto do Curso de Graduação e da Escola de Direito do Centro Universitário do Estado do Pará CESUPA. Coordenador da Especialização em Direito Processual Civil e do Trabalho do CESUPA/ESA. Professor Convidado da Escola Superior de Magistratura do Estado do Pará e da Escola Superior de Advocacia do Estado do Pará. Membro da Associação Norte e Nordeste de Professores de Processo - ANNEP.
} 
A Lei 13.105/2015, que instituiu o novo Código de Processo Civil, em vigor a partir de março de 2016, estabelece um conjunto de dispositivos que visam à construção de um sistema de vinculação de precedentes no ordenamento jurídico brasileiro. A previsão legal dessa pretensão de sistema é desafiadora em diversos aspectos e, dentre eles, se apresenta o problema focalizado no presente estudo: como justificar, do ponto de vista da teoria do direito, a instituição de um sistema precedentalista no Brasil?

Para resolver o problema acima suscitado, é necessário apresentar uma série de questões que permeiam a temática dos precedentes, considerando as vicissitudes do direito brasileiro. É necessário esclarecer inicialmente que a imposição legal de força normativa a atos judiciais, tais como os precedentes e súmulas, não significa a existência de um sistema de vinculação de precedentes, tampouco que essa determinação legal é reflexo do robustecimento de uma sólida teoria dos precedentes no Brasil.

Com efeito, a legislação atual prevê uma série de regras e princípios que determinam que atos judiciais possuem força vinculante, e devem ser obrigatoriamente observados no julgamento de casos futuros. O precedente judicial, aqui sumariamente definido como a decisão judicial tomada a partir de um caso concreto, cujo(s) fundamento(s) determinante(s) sirva(m) como diretriz(es)/comando(s) para a apreciação de casos futuros semelhantes (TUCCI, 2004), é um elemento característico de todo e qualquer ordenamento jurídico, independentemente de sua tradição originária (DAVID, 2002). A existência de precedentes judiciais é decorrência do exercício da atividade jurisdicional. O que se observa de traço distintivo no ordenamento processual brasileiro contemporâneo é a sistematização de normas que estabelecem eficácia vinculante aos precedentes judiciais.

É importante esclarecer que a previsão legal de eficácia vinculante para atos judiciais não é o traço inovador do Código de Processo Civil atual ${ }^{3}$. O que se apresenta vindouro é a pretensão - a partir de sistematização de um conjunto estruturado de normas - da construção de um sistema de vinculação de precedentes.

A criação do sistema, porém, não pode ser reconhecida com a simples previsão legal de que precedentes judiciais devem ser obrigatoriamente observados por juízes e tribunais em casos semelhantes futuros (BUSTAMANTE, 2012). Ainda que a legislação atual tente conjugar vários dispositivos acerca da eficácia normativa dos precedentes, impondo que os

\footnotetext{
${ }^{3}$ O Código de Processo Civil de 1973, revogado pelo Código atual, sofreu, a partir de 1994, uma série de alterações com o objetivo de instituir eficácia vinculante, persuasiva, obstativa e até autorizante para atos judiciais, especialmente para as súmulas (SOUZA, 2007) editadas pelo Supremo Tribunal Federal e pelo Superior Tribunal de Justiça.
} 
tribunais devam manter o seu conjunto de decisões judiciais estável, íntegro e coerente (926, CPC), estabelecendo a necessidade de que as decisões judiciais devam ser adequadamente fundamentadas com rigor técnico na aplicação dos precedentes e súmulas $\left(489, \S 1^{\circ}, \mathrm{V}\right.$ e VI, CPC), isso é insuficiente para a estruturação de um verdadeiro sistema precedentalista. A construção desse sistema exige dois esforços elementares, quais sejam: a) a compreensão e definição de uma teoria dos precedentes judiciais, decorrente de uma percepção mais ampla da própria teoria do direito; b) a formação de juristas aptos a criarem a aplicarem adequadamente os precedentes judiciais.

No presente estudo, o primeiro dos dois esforços acima apontados será empreendido: contribuir para a definição de uma justificação teórica do sistema precedentalista nacional, a partir da teoria do direito. Não se olvida aqui da importância do segundo esforço (formação adequada dos juristas), mas, para uma maior consistência na investigação, realizou-se um recorte metodológico, buscando-se solução para a questão de fundo teórico do nosso sistema precedentalista.

Para o desenvolvimento do estudo, a fonte de conhecimento está sedimentada no estudo doutrinário dos referenciais teóricos selecionados como guias de análise do problema, com ênfase nas ideias de Ronald Dworkin, sem prejuízo do diálogo com outros autores que podem contribuir para uma compreensão teórica do nosso sistema de precedentes.

\section{AS ORIGENS DO SISTEMA JURÍDICO BRASILEIRO: UMA BARREIRA AO SISTEMA PRECEDENTALISTA?}

A doutrina identifica o Brasil como um país formado a partir da tradição jurídica romano-germânica, inserido na família do Civil Law (LOSANO, 2007), na qual se afirma que a lei impera como fonte central do direito, relegando aos precedentes papel secundário, partindo-se da premissa de que as decisões anteriores proferidas pelos tribunais em casos similares, quando muito, apenas orientaram o caminho a ser seguido nos casos seguintes. Diante de tal identificação, é imperioso afirmar que a formação de um sistema de precedentes no Brasil terá que superar diversas dificuldades, decorrentes da própria ausência de costume ${ }^{4}$ na observância dos precedentes como fontes do direito (LIMA FILHO, 2016).

\footnotetext{
4 “Uma cultura (adequada) de precedentes — indispensável à sua correta aplicação — não advirá de uma epifania coletiva, ensejada pelo Novo Código, na qual, no instante de sua promulgação, seria revelado aos aplicadores do direito - advogados privados e públicos, juízes, membros do Ministério Público etc. — a melhor forma de analisar e os métodos de argumentação e aplicação adequados para o manejo dos precedentes judiciais. Não, tempo e estudo são essenciais. É de se anotar, inclusive, que, conquanto as cláusulas gerais não sejam uma
} 
Nos sistemas jurídicos com tradição firmada no stare decisis, formados sob os auspícios da tradição jurídica do Common Law, foi construída paulatinamente a ideia de que o ordenamento jurídico deve ser pautado na observância dos precedentes judiciais (MARINONI, 2014), com respeito a valores como a previsibilidade e a racionalidade da função jurisdicional. A força normativa dos precedentes, nesses sistemas, decorreu de opções históricas, não necessariamente legislativas, a partir da compreensão de que a aplicação das teses firmadas em decisões passadas era importante para manter a coerência do próprio sistema (DUXBURY, 2008).

A partir de então, pode-se afirmar que a simples previsão legal da força normativa dos precedentes não garantirá a correta aplicação dos mesmos. Mas também é possível afirmar que ausência de tradição no direito brasileiro na adoção dos precedentes como norma não é barreira intransponível para a formação de um sistema precedentalista. A afirmação dessa impossibilidade decorre de uma falsa percepção de pureza dos sistemas jurídicos contemporâneos, numa estanque classificação ilusória dos ordenamentos jurídicos dentro da dicotomia Civil Law x Common Law. A doutrina, entretanto, já tem se manifestado sobre a incoerência dessa rígida distinção. Nesse sentido,

Não há dúvida que o papel do atual juiz do Civil Law e, principalmente, o do juiz brasileiro, a quem é deferido o dever-poder de controlar a constitucionalidade da lei no caso concreto, muito se aproxima da função exercida pelo juiz do Common Law, especialmente a da realizada pelo juiz americano. Acontece que, apesar da aproximação dos papéis dos magistrados de ambos os sistemas, apenas o common law devota[va] respeito aos precedentes - o que se afigura altamente noviço aos sistemas de distribuição de justiça, à afirmação do Poder e à estabilidade do direito no Brasil. (MARINONI, 2011, p. 19).

Percebe-se um caminho de aproximação entre os grandes sistemas jurídicos, que não são encontrados em seu estado puro em nenhum país ocidental democrático da atualidade. É verdade que no Brasil a aplicação da força normativa dos precedentes não decorrerá de um amadurecimento natural do sistema jurídico, mas sim de imposição legislativa. Parte da doutrina chega a afirmar que o direito brasileiro está passando por um processo de commonlização (STRECK; ABBOUD, 2013), sofrendo forte influência do direito anglosaxão, deixando de estar sob o império da lei, e passando ao império dos precedentes, como fontes centrais para a extração de normas jurídicas. Tal afirmação, no entanto, parte da percepção equivocada de pretensa pureza dos sistemas jurídicos.

novidade, até os dias atuais vê-se comumente a dificuldade dos aplicadores em lidar com a sua aplicação. Tentativa e erro fazem parte de uma mudança jurídica e, pois, cultural.” (BURIL; PEIXOTO, 2014) 
A globalização, a evolução social e cultural, a ascensão jurídica dos direitos fundamentais e a superação da premissa liberal de que o juiz tinha função exclusiva de aplicador da lei fizeram surgir um novo paradigma de interpretação, embasado na ideia de que é impossível aplicar a lei — ou qualquer outra fonte do direito — para a solução de um caso concreto sem realizar ato interpretativo ${ }^{5}$. Não em virtude da pobreza da lei, mas pela necessidade de atribuir ao Judiciário um papel construtivo na concretização dos direitos fundamentais (BRITO FILHO, 2008), as decisões judiciais passaram a servir de importante elemento integrativo dos sistemas jurídicos da família romano-germânica, inclusive no Brasil. Por isso, e também pela opção político-legislativa de atribuir força normativa aos precedentes, é necessário adotar uma adequada teoria dos precedentes para o ordenamento jurídico nacional.

\section{ALgUMAS POSSIBILIDADES TEÓRICAS PARA JUSTIFICAR O SISTEMA PRECEDENTALISTA BRASILEIRO}

Além das ideias de Ronald Dworkin, que constituem o cerne da justificação teórica do sistema precedentalista brasileiro proposto no presente estudo, dois outros doutrinadores, particularmente no campo da teoria dos precedentes, têm tido aceitação considerável dentre os juristas brasileiros para fundamentar a instituição da vinculação de atos judiciais no Brasil. Suas ideias serão apresentadas de forma bastante simplificada, pois não se almeja discuti-los aqui, mas apenas demonstrar como o estudo dessas teorias também pode influenciar a formação do sistema brasileiro.

Por que esperamos que os tribunais sigam ou obedeçam decisões do passado? Para Frederick Schauer (2009), a observância dos precedentes decorre de um compromisso social firmado na ideia de aprendizado com o passado, que leva os juízes do presente a analisarem os casos atuais de acordo com as experiências formadas nos julgamentos de casos anteriores. Mas essa ideia não é suficiente para justificar a vinculação das decisões passadas aos casos presentes e futuros. Quando muito, a noção de compromisso social apenas orienta os juízes do

\footnotetext{
5 “A forma de interpretação que estamos estudando - a interpretação de uma prática social — é semelhante à interpretação artística no seguinte sentido: ambas pretendem interpretar algo criado pelas pessoas como uma entidade distinta delas, e não o que as pessoas dizem, como na interpretação da conversação, ou fatos não criados pelas pessoas, como no caso da interpretação científica. (...) A interpretação das obras de arte e das práticas sociais, como demonstrarei, na verdade, se preocupa essencialmente com o propósito, não com a causa. Mas os propósitos que estão em jogo não são (fundamentalmente) os de algum autor, mas os do intérprete. Em linhas gerais, a interpretação construtiva é uma questão de impor um propósito a um objeto ou prática a fim de torná-lo o melhor exemplo possível da forma ou do gênero aos quais se imagina que pertençam". (DWORKIN, 1999, p.63-64)
} 
presente a aplicarem as razões de decidir de casos semelhantes julgados no passado. Há algo além da simples relação temporal entre os casos (precedente e presente) que justifica a sua vinculação. Para Schauer (1991), esse algo além seria a recorrência da aplicação das razões do precedente, a ensejar a formação de uma regra jurídica a moldar condutas. Em outras palavras, a vinculação decorre do fato social de que as pessoas começam a ordenar as suas condutas a partir das prescrições gerais extraídas das razões de decidir dos precedentes, que se constituem como regras que moldam o agir das pessoas em geral, e es sas pessoas esperam que os juízes, na análise de casos semelhantes ao precedente, apliquem essas regras.

Segundo ele [Shauer], nos sistemas de common law, em que os juízes decidem aplicando os princípios que justificam decisões anteriores, algumas dessas justificativas tornam-se recorrentes com o passar do tempo, levando ao desenvolvimento de um conjunto de prescrições gerais que aparecem como regras e, assim, são tratadas pelos juristas. Embora tais regras não estejam codificadas, elas são coercitivas e vinculam os juízes. (MAUES, 2012, p. 596)

Nessa perspectiva, os tribunais observam os casos passados e aplicam suas razões de decidir não porque concordam necessariamente com elas, mas porque elas se constituem como regras gerais de conduta enraizadas no ordenamento jurídico das quais se espera aplicabilidade nos casos futuros. É esse o elemento constitutivo da força vinculante dos precedentes, que se difeririam de meras experiências dos tribunais, pois as experiências não necessariamente devem ser repetidas em todos os casos futuros, mas os precedentes sim, porque são regras de conduta constituídas no tempo.

Neil MacCormick (2006) é outro doutrinador que dispensa parte de sua teoria da argumentação jurídica ao estudo da força normativa dos precedentes. Para este autor, tal como para Ronald Dworkin (1999), é impossível dissociar a abordagem da teoria do direito das práticas judiciais, e a partir da análise do raciocínio empreendido pelos juízes ingleses e escoceses revelado nas decisões dos tribunais, busca encontrar a racionalidade inerente a esses sistemas jurídicos.

A partir de então, o autor desenvolve uma teoria institucionalista que identifica no precedente o elemento que atribui coerência ao sistema jurídico (BUSTAMANTE, 2012). Ao deixar claro que sua teoria tem uma finalidade ao mesmo tempo descritiva e normativa ${ }^{6}$,

\footnotetext{
6 "Isto posto, uma pergunta imediatamente se apresenta a respeito do tipo de investigação no qual estamos embarcando: ela é acerca de normas ou é em si normativa? (...) Entre essas duas possibilidades existe um meiotermo, que é o caminho que pretendo seguir. Não é minha meta nem minha pretensão fornecer uma descrição exaustiva de todos os elementos possíveis na argumentação jurídica como se apresentam concretamente nos
} 
MacCormick entende que só é possível compreender a forma como os juízes decidem interpretam o direito - a partir da análise de suas práticas, delas extraindo de forma mais precisa o conteúdo do direito. Nesse sentido, a existência de precedentes é essencial do ponto de vista da formação do direito, pois só mediante a extração das normas decorrentes dos precedentes é possível construir um sistema jurídico.

Como dito de início, não é possível pensar em jurisdição sem pensar na formação de precedentes. Mas o que levaria a crer que as decisões proferidas pelos tribunais no passado devem ser observadas pelos juízes do presente e do futuro? Adotando uma concepção de justiça elaborada em John Rawls (2008) ${ }^{7}$, MacCormick reconhece nos precedentes o elemento que viabiliza a importância de tratar as pessoas com equidade, pois proferir respostas para os casos presentes de acordo com os mesmos fundamentos que foram utilizados para interpretar casos passados semelhantes, além de atribuir coerência ao sistema jurídico, atribui um sentido de justiça à atuação dos tribunais.

O tribunal que hoje decide um caso específico entre individuais deveria levar em conta seu dever, pelo menos seu dever inicial, de decidir o caso em termos compatíveis com decisões anteriores sobre as mesmas questões ou questões semelhantes. No mínimo, a justiça formal exige que, exceto por fortes razões, ele não decida o caso atual de uma forma diferente da adotada em suas decisões anteriores em casos semelhantes. Ao decidir esse caso, o tribunal não terá então o dever - de igual importância, de levar em conta o precedente que estará estabelecendo para casos ainda por surgir? O dever que tenho de tratar casos semelhantes de modo semelhante implica que devo decidir o caso de hoje com fundamentos que eu esteja disposto a adotar para a decisão de casos semelhantes no futuro, exatamente tanto quanto implica

tribunais e aparecem registrados nas coletâneas de jurisprudência. De modo semelhante, não me isolo das realidades dos sistemas jurídicos e promulgo de minha posição altaneira meus próprios decretos arbitrários sobre como juízes e advogados deveriam debater. Pelo contrário, apresento uma exposição de certas características da argumentação jurídica que se encontram realmente exemplificadas nas coletâneas de jurisprudência, e explico as razoes pelas quais creio que elas devam ser características fundamentais da argumentação jurídica, tendo em vista sua função." (MACCORMICK, 2006, p. 16).

${ }^{7}$ Parte-se do pressuposto de que é necessário que as sociedades respeitem as liberdades de cidadania igual dos seus indivíduos, de modo que os anseios de bem-estar social não são justificáveis se violarem em demasia os direitos individuais. Desse modo, numa sociedade minimamente ordenada são necessários alguns mecanismos de distribuição da justiça, capazes de garantir o bem-estar de modo geral, sem ferir os direitos mínimos dos indivíduos. Para que isso seja possível é necessária a existência de uma concepção mínima, mas pública e determinada, de justiça, ainda que isso não seja assim tão simples. "Quem defende concepções distintas de justiça pode, então, concordar que as instituições são justas quando não fazem distinções arbitrárias entre pessoas na atribuição dos direitos e deveres fundamentais, e quando as leis definem um equilíbrio apropriado entre as reivindicações das vantagens da vida social que sejam conflitantes entre si. Os homens concordam com essa descrição de instituições justas, contanto que as ideias de distinção arbitrária e de equilíbrio apropriado, que estão contidas no conceito de justiça, estejam abertas para que cada um as interprete segundo os princípios de justiça que aceita. Esses princípios põem em destaque que similaridades e que diferenças entre as pessoas são importantes na atribuição dos direitos e dos deveres, e especificam qual é a divisão de vantagens apropriada". (RAWLS, 2008, p. 6) 
que hoje eu devo levar em consideração minhas decisões anteriores em casos semelhantes no passado. (MACCORMICK, 2006, p. 96)

Desse modo, desenvolve sua teoria institucionalista firmada na percepção de que um sistema jurídico justo exige o dever de coerência dos tribunais, que só é possível de ser cumprido com a observância dos precedentes como normas de justiça.

\section{A TEORIA DO DIREITO COMO INTEGRALIDADE DE RONALD DWORKIN}

Outro suporte teórico relevante para a análise da aplicação de precedentes com força normativa é a teoria de Ronald Dworkin. Nominada de "direito como integridade" (DWORKIN, 1999), ela aceita o direito e as pretensões juridicamente asseguradas nas decisões passadas; supõe que a vinculação beneficia a sociedade não apenas por uma questão de segurança jurídica, mas por assegurar um tipo de igualdade que torna a comunidade mais genuína e aperfeiçoa sua justificativa moral para exercer o poder político; considera que os direitos que decorrem de decisões anteriores têm valor legal quando procedem dos princípios de moral pessoal e políticas que as decisões pressupõem a título de justificativa. Em outras palavras, a limitação da discricionariedade interpretativa dos juízes na aplicação do direito encontra fundamento na própria atuação jurisdicional, mais precisamente nos precedentes, casos paradigmas julgados no passado e que orientam a interpretação a ser realizada nos casos presentes e futuros. Para Dworkin, uma aplicação adequada dos precedentes, vistos como princípios (MAUÉS, 2012) que sedimentam a integridade, é essencial para a oxigenação do direito, possibilitando que divergências acerca de conceitos jurídicos sejam superadas através de consensos históricos pré-estabelecidos entre os intérpretes do presente e os juízes do passado, com a finalidade de outorgar à atividade jurisdicional maior segurança, igualdade e previsibilidade.

Para analisar com mais detalhes a teoria de Ronald Dworkin, importante situá-la em sua crítica ao positivismo jurídico, paradigma que sustentou os sistemas jurídicos modernos. Nesse contexto, importante mencionar que a guinada linguística, concebida como construção intersubjetiva do mundo por meio da linguagem e do horizonte histórico-dialético, implodiu o positivismo jurídico, que ora tratava a norma como um a priori ao prescindir de interpretação à compreensão de seu sentido epistemológico, ora como um absoluto a posteriori ao estabelecer um sentido criacionista. Concebeu o autor um modelo que o inclui em um arquétipo teórico da coerência ou racionalidade substancial, ao partir da ideia de interpretação 
construtiva, à luz de uma leitura axiológica das normas jurídicas, evitando os riscos de uma arbitrariedade valorativa e de decisionismos.

Em sua teoria descritivo-justificadora, Dworkin tenta conciliar postulados que, historicamente, foram considerados como inconciliáveis: trata-se da existência de juízos interpretativos que acenam à dimensão moral do direito e da possibilidade de que os mesmos possam ter um caráter objetivo, o que conduz à ideia de segurança e previsibilidade, outrora incompatíveis com dimensões de moralidade, justiça e equidade. Para tanto, parte da ideia de que as perguntas sobre o que é o direito (perspectiva descritiva) e o que deve ser o direito (justificação moral e crítica) estão entrelaçadas tanto na prática como na teoria do direito.

Segundo sua teoria, a interpretação ocorre dentro de uma comunidade e se move no sentido de afirmar a coerência global de um sistema normativo e sua consistência narrativa, o que acena, inexoravelmente, a uma inclinação para a ética. A teoria de Dworkin destina-se a construir um modelo de interpretação judicial que ofereça uma moralidade de inspiração, uma nova objetividade para o discurso jurídico e um novo sentido para a prática jurídica.

A crítica do pressuposto de distinção rígida e separação conceitual entre o direito e a moral, entre descrição e justificação, é um dos focos da crítica de Dworkin ao positivismo. Nota-se o afastamento à epistemologia amoral do positivismo jurídico e uma aproximação a uma teoria do direito que vê a prática jurídica como a expressão de uma moralidade pública subjacente. Para ele, o direito não se resume a um conjunto de regras vinculadas a um pedigree, mas incorpora princípios decorrentes da moralidade política. A argumentação jurídica invoca e utiliza princípios que os tribunais desenvolvem mediante processos argumentativos e criação de precedentes. Estes princípios são essencialmente morais e, como consequência, a argumentação jurídica passa a depender da argumentação moral. A decisão judicial é, pois, um constructo interpretativo, não arbitrariamente construtivista, porque é limitado pelos princípios e sua moralidade institucionalizada.

Ao atribuir significativa relevância aos princípios morais no âmbito da argumentação jurídica, passa a defender a falsidade da tese central do positivismo de separação entre direito e moral. Por essa tese, há autores que interpretam sua obra como uma nova versão do jusnaturalismo. Mas Dworkin recusa o modelo de argumentação típico do naturalismo, porque não crê na existência de um direito natural que seja constituído por um conjunto de princípios unitários, universais e imutáveis, independentemente do mundo concreto dos fatos e das ações. 
Parte do pressuposto de que a argumentação moral se caracteriza pela construção de um conjunto consistente de princípios. A virtualidade proposta por Dworkin acerca dos princípios jurídicos resulta em sua ubiquidade, ao não limitar-se a casos marginais de obscuridade ou ausência de norma. Trata-se de uma tarefa reconstrutivo-racional do pensamento moral que se estende ao pensamento jurídico.

Dworkin, ao rejeitar o positivismo jurídico e o jusnaturalismo, constrói o seu próprio aparato analítico: o modelo da reconstrução racional aplicado ao conhecimento do direito. Importante destacar que a teoria de Dworkin aspira à superação da herança maniqueísta e obsoleta entre o mundo da natureza retratado pelo direito natural e o mundo da cultura expresso pelo direito positivo. Segundo Dworkin, o intérprete deveria ter condições de escapar ao dilema entre o contexto da descoberta do direito, como valor objetivo-natural, e o contexto da criação. A atividade interpretativa não deveria se mostrar nem como invenção do direito nem como simples reprodução dos limites postos pelas normas.

Partindo dessa ideia de repúdio à descoberta e à invenção ao apresentar a possibilidade de criação do direito, importante registrar o estilo argumentativo de Dworkin, que se utiliza de construções triádicas em que duas proposições antagônicas se reconciliam finalmente em uma terceira que supera os inconvenientes das duas em conflito, reunindo e exaltando suas vantagens. Assim ocorre com a superação do binômio: jusnaturalismo x juspositivismo, superado pela perspectiva interpretativa do direito; liberalismo $\mathrm{x}$ igualitarismo, afastado pela ideia de que apenas uma comunidade liberal pode alcançar a igualdade; convencionalismo x pragmatismo, desconstruído em face a um modelo que conjuga a segurança do convencionalismo com a flexibilidade do pragmatismo, expressos no direito como integridade; sistema estático x sistema dinâmico, ao apresentar uma tentativa de reconciliação e síntese entre um sistema baseado em axiomas e em um valor prévio e um sistema pautado em sucessivas delegações do poder de produzir normas jurídicas, ao desenvolver um sistema com conteúdos estáticos que se conjugam com procedimentos dinâmicos e institucionais.

Registre-se que Ronald Dworkin é representante de um liberalismo progressista não conservador. Para ele, a garantia dos direitos individuais é uma das funções mais importantes do sistema jurídico. Na defesa de sua teoria, opõe-se ao utilitarismo, que se baseia nos fins coletivos aos quais devem ser subordinados os direitos individuais. Segundo Dworkin, os objetivos sociais apenas são legítimos se respeitam os direitos individuais. A sua crítica ao 
positivismo jurídico, que é a manifestação por excelência da teoria jurídica liberal tradicional e, igualmente, a crítica ao utilitarismo, que tem sido uma das manifestações da filosofia política liberal, o conduzem a um liberalismo progressista pautado em uma fundamentação igualitária, é dizer, um liberalismo igualitário preocupado em garantir os direitos de minorias e conciliar demandas de liberdade com proposições de igualdade.

À luz de sua teoria, são três as virtudes da moral política, é dizer, valores que o direito visa materializar: a) equidade, compreendida como a dimensão procedimental das decisões políticas. Trata-se da virtude que demanda uma distribuição correta ou equitativa do poder político e se realiza em procedimentos que estabelecem a todos os cidadãos uma influência semelhante no processo de tomada de decisão; b) devido processo legal, princípio relativo à prática de aplicação do direito e que reclama retidão e trato igual na aplicação da norma jurídica; c) justiça, que é a dimensão substantiva das decisões políticas. Acena à solução adequada dos problemas morais e políticos em torno do seu conteúdo.

Os dois primeiros valores são procedimentais e conformam a ideia de igualdade formal com independência do sentido material de suas proposições. Em razão disso, Dworkin une as duas perspectivas formais na virtude da equidade e preceitua as exigências de integridade do direito como a persecução de um esquema coerente de justiça e equidade na relação devida. A coerência do sistema, no entanto, não se resume a coerência entre equidade em sentido amplo e justiça. A integridade remete à ideia de coerência global da totalidade dos princípios fundamentais da ordem jurídica.

Assim, em algumas ocasiões, é possível que, em nome da coerência global, as duas virtudes da moral política não caminhem juntas. Ressalte-se que não há um padrão que estabeleça a prevalência da justiça sobre a equidade nem da equidade sobre a justiça. Para resolver eventuais contraposições entre justiça e equidade, é que o direito como integridade, baseado na ideia de coerência como virtude jurídica, surge para dirimir esse conflito. Haverá momentos em que a justiça prevalecerá em face da equidade; em outros, prevalecerá a equidade em detrimento da justiça. Trata-se da ideia de que a integridade é uma virtude independente da justiça e equidade e, ao mesmo tempo, a virtude que as ordena e serve de princípio fundamental do sistema jurídico.

Essa é a concretização do ideal de integridade: a prevalência da decisão mais coerente com o ordenamento jurídico, a partir do cotejamento com as decisões passadas e com o respeito aos ideais de equidade e justiça de uma comunidade. Quanto às decisões do 
passado, se as mesmas não mais se justificam, devem ser alteradas em nome da própria integridade e coerência. Falar com uma só voz, comprometendo-se a construir uma única solução jurídica que seja o reflexo da prática jurídica como um todo.

Esse ideal de integridade está relacionado à ideia de interpretação construtiva, que se explica através da analogia que Dworkin realiza do direito com a interpretação da literatura, é dizer, do juiz com o crítico literário, que é, ao mesmo tempo, autor de um romance. A doutrina de um precedente é semelhante à construção de um romance em cadeia, situação segundo a qual um grupo de romancistas escreve um livro que nunca é concluído. Cada autor seria, ao mesmo tempo, intérprete e criador. Como autor do romance, ele vai continuar a escrever uma história já iniciada por outro, mas, ao mesmo tempo, fazendo uma crítica, na medida em que interpreta o que já fora escrito, continuando adiante a história. A exigência de integridade com os capítulos anteriores não exclui a possibilidade de afastar-se de alguns de seus elementos, desde que tais elementos possam ser identificados como erros na direção da melhor obra possível (DWORKIN, 2001, p. 235-249).

Nessa perspectiva, a arte consiste em criar um sutil equilíbrio entre acrescentar algo novo e propiciar a continuidade. Da mesma forma, deverá o juiz levar em consideração o passado, interpretando a história jurídica anterior, porque tem a responsabilidade de levar adiante a incumbência que tem em mãos e não partir em alguma nova direção, ao mesmo tempo em que se projeta para o futuro para chegar à melhor justificação possível da prática jurídica como um todo (melhor peça de política possível), tal como a melhor interpretação de uma obra de arte que a apresente como a melhor e mais valiosa obra de arte possível.

Nota-se uma estreita conexão entre a interpretação de uma obra e as convicções sobre como deve ser uma boa obra de arte; entre a interpretação de uma norma e as convicções sobre como deve ser a política, considerando que o direito, ao contrário da literatura, não é um empreendimento artístico, mas um empreendimento político cuja finalidade precípua é "coordenar o esforço social e individual, ou resolver disputas sociais e individuais, ou assegurar a justiça entre os cidadãos e entre eles e seu governo, ou alguma combinação dessas alternativas”. E como prática político-interpretativa, deve demonstrar o seu valor em termos políticos, demonstrando o melhor princípio ou política a que serve (DWORKIN, 2001, p. 239).

A integridade, para Dworkin, concebe o direito como um modo de aperfeiçoamento da comunidade política, como atividade construtiva de dar sentido ao passado ao mesmo 
tempo em que se projeta para o futuro, a partir de uma reinterpretação e revitalização das práticas jurídicas, mediante o aprofundamento de seu fundamento moral e a reinterpretação construtiva de sua tradição jurídica. Nesse sentido, "o Direito como integridade começa no presente e só se volta para o passado na medida em que seu enfoque contemporâneo assim determine". (DWORKIN, 1999, p. 271-331). O que se busca no passado é a composição coerente de princípios de uma dada comunidade.

À luz desse entendimento, uma proposição jurídica é verdadeira se é mais coerente do que outras com o conjunto de proposições que oferecem a melhor versão da prática jurídica. Nas palavras de Dworkin, "segundo o Direito como integridade, as proposições jurídicas são verdadeiras se constam, ou se derivam, dos princípios de justiça, equidade e devido processo legal que oferecem a melhor interpretação construtiva da prática jurídica da comunidade". (DWORKIN, 2001, p. 219-272). Isso significa que não existe algoritmo ${ }^{8}$ algum para confirmar se uma interpretação ajusta-se adequada e objetivamente às práticas jurídicas de um certo caso e contexto. A escolha da decisão correta dentre os vários sentidos, fundamentalmente diferentes, deve ser decidida como uma questão de teoria política, que se afasta de qualquer elemento relativo à intencionalidade do legislador.

A intenção do autor no âmbito do direito é substituída por uma interpretação que é, para Dworkin, essencialmente política, o que se observa com a interpretação da cláusula de igualdade de proteção da Constituição dos Estados Unidos. Interpretar o sentido de igualdade presente nessa cláusula não é possível sem uma certa teoria correlata sobre igualdade política e sem a compreensão adequada entre as conexões estabelecidas entre a ideia de igualdade e as exigências de justiça, e isso demonstra que a história jurídica do último meio século é, em parte, uma história de interpretações que envolvem, necessariamente, dimensões de moralidade política.

Juristas conservadores apelaram ao passado e às intenções do constituinte, em busca da manutenção do status quo segregacionista e, consequentemente, de uma leitura menos igualitária da Décima Quarta emenda à Constituição americana, acusando a corrente contrária, progressista, que enfatizava uma perspectiva mais ampla de igualdade, de criar, arbitrariamente, direito novo. Tratava-se de uma vociferação com o escopo de ocultar a função que as próprias convicções políticas exercem na escolha do estilo interpretativo. No

\footnotetext{
${ }^{8}$ Sequência lógica, finita e que contém instruções que devem ser seguidas para resolver um problema ou executar uma tarefa.
} 
entanto, resta evidente a ideia segundo a qual valer-se de uma teoria política não é uma distorção da interpretação, mas parte propriamente do que significa interpretação.

Seguindo esse entendimento, o direito como integridade critica o convencionalismo, comumente associado ao positivismo jurídico, ao recusar a ideia do direito como simples convenção, porque considera que a ordem de direitos e responsabilidades decorre da própria convivência social e política e não de um estabelecimento arbitrário de decisões políticas convencionalmente estabelecidas no passado que se baseiam na segurança jurídica (como Hart) e na autoridade (como Raz) para justificar a sua coerção. Nega, portanto, que as manifestações do direito sejam meras descrições factuais do convencionalismo voltadas para o passado. Embora o convencionalismo promova a máxima realização das convenções instituídas no passado, em nome da previsibilidade e, por isso mesmo, imponha uma restrição à atuação dos juízes para evitar que invoquem suas próprias convicções morais e políticas, não promove o devir, o necessário movimento para adiante.

Dworkin recusa, igualmente, o raciocínio pragmático-utilitarista, usualmente relacionado ao realismo jurídico, que nega o passado, projetando-se apenas para o futuro por intermédio de programas instrumentais do pragmatismo jurídico, sem nenhuma restrição derivada da história jurídica anterior, porque distingue claramente o raciocínio jurídico do político, não subordinando questões de moral política a considerações teleológico-contextuais. Embora o pragmatismo ofereça flexibilidade, não mantém compromisso com o núcleo essencial da legalidade na proteção dos direitos, na medida em que é nociva à ideia de preservação a pautas prévias, ao considerar que a melhor reconstrução da prática jurídica seja aquela que realiza os juízes, decidindo in concreto, a partir de suas crenças e vontade (DWORKIN, 1999, p. 275-279).

Cada uma dessas perspectivas fracassa em virtude do seu nítido caráter maniqueísta. O convencionalismo e seus argumentos retrospectivos e de consistência ao passado, ignora os valores morais e de justiça implicados na prática jurídica. E ao fazê-lo, acaba por negar os valores de segurança, certeza e previsibilidade que pretende garantir. Isso porque o convencionalismo exorta o intérprete a que recorra à literalidade da convenção, notadamente em sua dimensão explícita. O problema é que, ao circunscrever o direito a priori em um âmbito tão limitado, notadamente ante a complexidade das sociedades contemporâneas, o recurso ao direito preeestabelecido e a fidelidade do juiz a essas convenções tornam-se inaplicáveis, conduzindo o intérprete a extrapolar os limites do direito válido, por meio do uso 
inevitável da discricionariedade judicial, o que transforma a segurança que almejava em sua antítese.

O pragmatismo e seus argumentos prospectivos de renovação da prática jurídica, da mesma forma, mas pelo motivo oposto, ao perseguir os valores do presente, independentemente das ataduras ao direito preexistente, ignora os imperativos de consistência e ajuste institucional importantes à tradição jurídica e à continuidade narrativa do direito como integridade. No entanto, ao sacrificar a realidade normativa preconstituída, acaba por negligenciar, no mais das vezes, a realização dos valores de justiça que pretendia consagrar.

Nesse sentido, Dworkin recusa, através de sua interpretação construtiva, a dualidade entre descobrir um direito preexistente, como no convencionalismo, e inventar (criar) um direito novo, como no pragmatismo, porque entende que a prática jurídica é mais bem compreendida quando se reconhece que as decisões judiciais fazem ao mesmo tempo as duas coisas e nenhuma delas. A melhor interpretação, necessariamente relacionada à teoria política, está a meio caminho entre o convencionalismo e o pragmatismo, tentando alcançar um equilíbrio entre o peso das decisões do passado e o peso do melhor argumento do presente, supondo que os juízes devem assumir uma visão omnicompreensiva do direito para dar conta da globalidade da prática jurídica e não meramente de decisões isoladas sem nenhuma conexão ou relação entre si.

À luz desse procedimento, o direito deve almejar a integridade, de modo a se formar um Estado ou uma comunidade que não seja regida apenas por regras, mas também por princípios, que são exigências da moralidade política. Note-se que a Constituição e sua dimensão principiológica resguardam os direitos fundamentais e impedem interferências indevidas, fruto de eventuais procedimentos majoritários de formação da vontade política, nesse âmbito de proteção constitucional, da mesma maneira que afastam a discricionariedade forte e o arbítrio ao julgamento, ao estabelecerem balizas racionais. Dworkin demonstra, assim, como obter racionalidade nas decisões jurídicas recorrendo aos princípios que estão, segundo o autor, fundamentados no próprio conceito de interpretação construtiva.

\section{DA TEORIA DO DIREITO À TEORIA DOS PRECEDENTES EM RONALD DWORKIN}

Dworkin (2002) defende que é importante o modo como os juízes decidem os casos, pois a adoção de um argumento em desfavor de outro pode fazer significativa diferença na 
vida da comunidade. A decisão de um juiz encarna não apenas a disposição de quem tem direito a algo, mas inclui um valor moral, que determina quem agiu de modo correto em determinada circunstância. Por essa razão, é importante saber o que os juízes pensam do direito, e sobre o que o modo de pensar deles é divergente. $\mathrm{O}$ argumento central apresentado por Dworkin para definir essa divergência é o seguinte: o direito possui uma peculiaridade em relação aos demais fenômenos sociais, é argumentativo ${ }^{9}$.

O fluxo de movimentação do direito na atualidade imprime aos juristas a necessidade de crença nas decisões judiciais, dados os debates contínuos sobre determinados assuntos. A antiga imagem do direito como simples matéria de fato dizia para não tomarmos ao pé da letra os votos proferidos pelos juízes nos casos difíceis; essa nova imagem tem o mérito notável de nos permitir, mais uma vez, acreditar no que dizem nossos juízes (DWORKIN, 1999).

Para que as práticas sociais possam ser reconhecidas, no entanto, há a necessidade de uma confluência de saberes, mínima o suficiente para que qualquer divergência seja legítima, mas não para que não haja divergência alguma. Só é possível realizar uma interpretação da prática social em si, desvinculada das intenções dos seus partícipes um a um, se o intérprete aderir à prática que se propõe compreender. Em outras palavras: a prática a ser interpretada determina as condições da interpretação.

Feita a explanação básica da ideia do direito como um conceito interpretativo/argumentativo, Dworkin apresenta alguns argumentos de base para a sua análise posterior, da integridade como um princípio autônomo e fundador da interpretação judicial. Inicialmente, parte do pressuposto de que todo julgamento de direito é um ato interpretativo. As influências que levam à convergência de opiniões entre juízes, além dos paradigmas do direito, são inerentes à natureza da interpretação. Além disso, o meio, os precedentes, e a formação jurídica inclinam a um pensamento convergente em uma medida mínima. Segundo o autor, "a dinâmica da interpretação resiste à convergência ao mesmo tempo que a promove, e as forças centrífugas são particularmente fortes ali onde as comunidades profissional e leiga se dividem em relação à justiça”. (DWORKIN, 1999, p. 110).

A interpretação judicial acaba sendo responsável pela oxigenação do direito, e as melhores teorias do direito são interpretações construtivas, pois buscam apresentar o conjunto

\footnotetext{
9 "Daí Dworkin sustentar, com razão, que não há linha precisa que divida a teoria do Direito (jusrisprudence) e a aplicação judicial do Direito (adjudication). (...) A razão dessa conexão intrínseca entre filosofia jurídica e prática jurídica está em uma particularidade específica do Direito, que o singulariza entre as práticas sociais: a prática jurídica, diferentemente de outros fenômenos sociais, é argumentativa." (BUSTAMANTE, 2012, p. 134135).
} 
de jurisdição em sua melhor luz, para alcançar o equilíbrio entre a jurisdição tal como o encontram e a melhor justificativa dessa prática. Assim, qualquer discussão prática sobre o direito é também uma discussão sobre o melhor fundamento a ser adotado, e logo, trata-se de uma questão interpretativa. A compreensão sistêmica do direito não é algo dado pela comunidade, como a estrutura jurídica em si (tribunais, normas, leis, etc), mas faz parte do problema interpretativo compreender o sistema jurídico.

Em alusão às questões jurídicas, sabe-se, por exemplo, que quando recebe uma causa, o juiz tem conhecimento de que já houve outros casos semelhantes julgados por outros juízes e que, em face desta complexidade de decisões, deve-se considerar cada uma delas como sendo parte de uma longa história do direito, tendo por necessidade a interpretação e, ao mesmo tempo, dar continuidade à história. ${ }^{10}$

O direito como integridade, portanto, exige que os magistrados admitam, na medida do possível, que o direito é estruturado por um conjunto coerente de princípios sobre a justiça, a equidade e o devido processo legal. A interpretação não pode ser desconsiderada neste quadro, pois ela tem como escopo mostrar o que é interpretado da melhor maneira possível e esta interpretação não deve levar somente em consideração as decisões anteriores, mas também o modo como estas decisões foram tomadas.

\section{CONCLUSÃO}

A partir de uma opção político-legislativa, buscar-se-á a instituição, no Brasil, de um sistema precedentalista. Com efeito, a inclusão no texto do Código de Processo Civil atual

\footnotetext{
${ }^{10}$ Para melhor explicar o que pretende demonstrar, Dworkin apresenta o personagem fantasioso chamado Hércules, sendo que este possui capacidade e paciência sobre-humanas, aceitando o Direito como integridade. Esse instrumento retórico irá marcar a obra dworkinana. O autor diz que Hércules tem que decidir sobre o caso difícil específico, e terá de levar em consideração os diversos precedentes levantados pelas partes, tendo em vista que cada uma delas hasteou precedentes favoráveis às suas respectivas teses. Hércules deve formar uma opinião própria sobre a questão em discussão. Deve o personagem encontrar alguma teoria coerente sobre os direitos legais, tal que um dirigente político com a mesma teoria pudesse ter chegado à maioria dos resultados que os precedentes relatam. "(...) Dworkin resolve construir a figura de um super juiz, com poderes acima dos humanos, que toma os direitos a sério (taking rights seriously) como uma questão de princípio (a matter of principle) no império do direito (law's empire). Ele se chama Hércules. Hércules está ciente de que sua função é a de intérprete e seu papel não é o de mero reprodutor do texto legal, considerando que Dworkin faz a associação da literatura para o direito, ao comparar os diversos momentos entre o ator e o seu crítico perante o juiz (chain of law). O crítico já representa o momento da interpretação, ou seja, da maneira como ele aprendeu a realidade da peça, assim ele a descreve. O juiz é esse crítico literário, e deve elaborar uma única resposta certa nas decisões que prolata." (GOES, 2004, p. 33-34). Ao analisar a situação formulada por Dworkin, Érika Juliana Dmitruk afirma que "ao estudar os precedentes, Hércules terá que distinguir sua força gravitacional nas decisões posteriores. A força gravitacional de um precedente, segundo Dworkin, repousa na equiidade, os casos semelhantes devem ser tratados do mesmo modo. Para definir a força gravitacional de um precedente, Hércules só levará em consideração os argumentos de princípio que justificam esse precedente" (DMITRUK, 2008).
} 
brasileiro de um conjunto de normas com o objetivo de formação de um sistema de precedentes vinculantes apresenta uma série de desafios aos juristas brasileiros. No entanto, partindo-se da premissa de que esse pretenso sistema precedentalista trará resultados positivos à jurisdição brasileira, é necessário encontrar um aporte teórico que lhe dê sustentação, em busca da melhor maneira de justifica-lo, bem como solucionar eventuais problemas decorrentes de sua aplicação.

Nesse estudo, a propõe-se a teoria do direito como integridade, de Ronald Dworkin, como o aporte teórico mais adequado para fundamentar a formação do sistema precedentalista brasileiro. Sem olvidar a importância de outras teorias jusfilosóficas relevantes, defende-se que o modelo criado pelo autor americano é o que melhor se adequa às pretensões de estabilidade, coerência e integridade do sistema jurídico brasileiro, a partir da formação do sistema precedentalista nacional.

É importante o modo como os juízes decidem os casos, pois a adoção de um argumento em desfavor de outro pode fazer significativa diferença na vida da comunidade. A decisão de um juiz encarna não apenas a disposição de quem tem direito a algo, mas inclui um valor moral, que determina quem agiu de modo correto em determinada circunstância. Por essa razão, é importante saber o que os juízes pensam do Direito, e sobre o que o modo de pensar deles é divergente. Decidir é, ao mesmo tempo, interpretar e aplicar.

A interpretação define não apenas por que as regras existem (valor), mas também o que, devidamente compreendida, elas agora requerem (conteúdo). Valor e conteúdo, no processo interpretativo, se confundem. A interpretação realizada em relação a algum ato ou norma irá influenciar necessariamente nas práticas a ele(a) ligadas.

Portanto, uma teoria da interpretação é uma interpretação prática dominante de usar conceitos interpretativos. Em outras palavras: a forma como cada sociedade interpreta as suas normas depende, inclusive, do conceito de interpretação adotado. "A forma de interpretação que estamos estudando - a interpretação de uma prática social — é semelhante à interpretação artística no seguinte sentido: ambas pretendem interpretar algo criado pelas pessoas como uma entidade distinta delas, e não o que as pessoas dizem, como na interpretação da conversação, ou fatos não criados pelas pessoas, como no caso da interpretação científica". (DWORKIN, 1999, p. 61)

Esse propósito é o de sempre tornar o nosso objeto de interpretação o melhor possível, mas o intérprete não é completamente livre ao compreender, pois está vinculado à 
tradição que cerca o objeto ou prática de interpretação. Os precedentes, portanto, seriam elementos da tradição jurídico, devendo serem aplicados a casos futuros não apenas por sua força tradicional, mas acima de tudo por estabelecem vínculos de estabilidade e coerência do próprio direito, visto como ato de constante (re)interpretação.

Nesse perspectiva, conclui-se que o aporte teórico apresentado por Ronald Dworkin, observando o direito como integridade, partindo da ideia de que o direito também é formado a partir da prática judicial, pode servir de importante justificação à pretensa formação do sistema precedentalista pátrio.

\section{REFERENCIAS}

ATAÍDE JÚNIOR, Jaldemiro Rodrigues de. Precedentes vinculantes e irretroatividade do direito no sistema processual brasileiro: os precedentes dos Tribunais Superiores e sua eficácia temporal. Curitiba: Juruá, 2012.

BARCELLOS, Ana Paula de. A eficácia jurídica dos princípios constitucionais: o princípio da dignidade da pessoa humana. Rio de Janeiro; Renovar, 2002.

BASTOS, Antônio Adonias. A estabilidade das decisões judiciais como elemento contributivo para o acesso à Justiça e para o desenvolvimento econômico. In: Revista de Processo. n. 227. P. 295-316. 2014.

BRITO FILHO, José Cláudio Monteiro de. Direitos Fundamentais Sociais: Realização e Atuação do Poder Judiciário. Revista do TRT $8^{\text {a }}$ Região. Belém. v. 41, n. 81. dez/2008.

BURIL, Lucas; PEIXOTO, Ravi. Levando os Precedentes a Sério. Disponível em: http://justificando.com/2014/08/14/levando-os-precedentes-serio/. Publicado em: Ago/2014.

BURLEY, Justine (ed). Dworkin: his critics with replies by Dworkin. Malden: Blackwell Publishing, 2004.

BUSTAMANTE, Thomas da Rosa de. Princípios, regras e conflitos normativos: uma nota sobre a superabilidade das regras jurídicas e as decisões contra legem. In: Revista Direito, Estado e Sociedade. n. 37. P. 152-180. 2010.

Teoria do Precedente Judicial: a justificação e a aplicação de regras jurisprudenciais. São Paulo: Noeses, 2012.

DAVID, René. O direito inglês. São Paulo: Martins Fontes, 2006.

2002.

. Os Grandes Sistemas de Direito Contemporâneo. São Paulo: Martins Fontes,

DE VITA. Álvaro. Justiça liberal: argumentos liberais contra o neoliberalismo. Rio de 
Janeiro: Paz e Terra, 1993.

DMITRUK, Erika Juliana. O princípio da integridade como modelo de interpretação construtiva do direito em Ronald Dworkin. Revista Jurídica da UniFil, ano V, nº. 4, 2008.

DUXBURY, Neil. The nature and anthority of precedent. Cambridge: Havard University Press, 2008.

DWORKIN, Ronald. A Justiça de Toga. São Paulo: Martins Fontes, 2010.

Justiça para Ouriços. Coimbra: Almedina, 2011.

Fontes, 2005.

. A Virtude Soberana. A Teoria e a Prática da Igualdade. São Paulo: Martins

. Levando os Direitos a Sério. São Paulo: Martins Fontes, 2002.

. Uma Questão de Princípio. São Paulo: Martins Fontes, 2001.

. O Império do Direito. São Paulo: Martins Fontes, 1999.

. “Juízes Políticos e Democracia”. In: O Estado de São Paulo, 26/abril, 1997.

GOES, Gisele Santos Fernandes. Princípio da Proporcionalidade no Processo Civil. São Paulo: Saraiva, 2004.

HOMCI, Arthur Laércio. A teoria igualitária de Ronald Dworkin e os aspectos da igualdade material no Brasil. Disponível em: http://www.andhep.org.br/anais/arquivos/Vencontro/paineis/painel05.pdf. Acesso em $21 \mathrm{mar}$ 2016.

O direito como integridade na prática interpretativa dos direitos humanos. Revista Saber Jurídico (CESUPA), v. 3, p. 01-19, 2012.

LEAL, Roger Stiefelmann. O efeito vinculante na jurisdição constitucional. São Paulo: Saraiva, 2006.

LIMA FILHO, Eduardo Neves. O uso dos precedentes judiciais no Brasil. Rio de Janeiro: Lumen Juris, 2016.

LOSANO, Mário G. Os grandes sistemas jurídicos: introdução aos sistemas jurídicos europeus e extra-europeus. São Paulo: Martins Fontes, 2007.

MACÊDO, Lucas Buril de. Precedentes judiciais e o direito processual civil. Salvador: JusPodivm, 2015.

MACCORMICK, Neil. Argumentação jurídica e teoria do direito. São Paulo: Martins Fontes, 2006. 
2003.

. Legal Reasoning and Legal Theory. Oxford: Clarendon University Press, . Pratical Reason in law and morality. Oxford: Clarendon University Press,

2008.

. Retórica e o Estado de Direito. Rio de Janeiro: Elsevier, 2008.

MARINONI, Luiz Guilherme. A ética dos precedentes: justificativa do novo CPC. São Paulo: Revista dos Tribunais: 2014.

. Precedentes Obrigatórios. 2 ed. São Paulo: Revista dos Tribunais, 2011.

MARINONI, Luiz Guilherme (Org.). A força dos precedentes: estudos dos Cursos de Mestrado e Doutorado em Direito Processual Civil da UFPR. 2 ed. Salvador: JusPodivm, 2012 .

MAUÉS, Antônio Moreira. Jogando com os Precedentes: Regras, Analogias, Princípios. Revista de Direito da Fundação Getúlio Vargas - FGV. São Paulo: Jul/Dez 2012.

MERRYMAN, John Henry; e PERDOMO, Rogélio Pérez. A Tradição da Civil Law: Uma introdução aos Sistemas Jurídicos da Europa e da América Latina. Porto Alegre: Sergio Antonio Fabris Editor, 2009.

MITIDIERO, Daniel. Cortes Superiores e Cortes Supremas. São Paulo: Revista dos Tribunais, 2013.

NOGUEIRA, Gustavo Santana. Precedentes Vinculantes no Direito Comparado e Brasileiro. 2 ed. Salvador: JusPodivm, 2014.

RAWLS, John. Uma teoria da justiça. Trad. Jussara Simões. 3 ed. São Paulo: Martins Fontes, 2008.

RODRIGUES JUNIOR, Otavio Luiz. Dogmática e Crítica da Jurisprudência (ou da vocação da doutrina em nosso tempo). In: Revista dos Tribunais. Vol. 891, p. 65. 2010.

SCHAUER, Frederick. Playing by the Rules. Oxford: Clarendon Press, 1991.

. Thinking Like a Lawyer. Cambridge: Havard University Press, 2009.

SOUZA, Marcelo Alves Dias de. Do precedente judicial à súmula vinculante. Curitiba: Juruá, 2007.

STRECK, Lênio Luiz; ABBOUD, Georges. O que é isto - o precedente judicial e as súmulas viculantes. Porto Alegre: Livraria do Advogado, 2013. 
TUCCI, José Rogério Cruz e. Precedente Judicial como fonte do Direito. São Paulo: Revista dos Tribunais, 2004.

VERBICARO, Loiane Prado. O ensino jurídico brasileiro e o direito crítico e reflexivo. 2007. Disponível em http://www.egov.ufsc.br/portal/sites/default/files/anexos/29843-298591-PB.pdf. Acesso em 12 nov 2016.

VILLEY, Michel. A formação do pensamento jurídico moderno. São Paulo: Martins Fontes: 2005.

WAMBIER, Teresa Arruda Alvim (Coord). Direito Jurisprudencial. Revista dos Tribunais: São Paulo, 2012.

ZANETI JR, Hermes. O valor vinculante dos precedentes. Salvador: JusPodivm, 2015. 